\title{
Taking stock of neighbourhood planning in England 2011-2016
}

Article

Accepted Version

Parker, G. and Salter, K. (2017) Taking stock of neighbourhood planning in England 2011-2016. Planning Practice and Research, 32 (4). pp. 478-490. ISSN 1360-0583 doi: https://doi.org/10.1080/02697459.2017.1378983 Available at https://centaur.reading.ac.uk/72693/

It is advisable to refer to the publisher's version if you intend to cite from the work. See Guidance on citing.

To link to this article DOI: http://dx.doi.org/10.1080/02697459.2017.1378983

Publisher: Taylor and Francis

All outputs in CentAUR are protected by Intellectual Property Rights law, including copyright law. Copyright and IPR is retained by the creators or other copyright holders. Terms and conditions for use of this material are defined in the End User Agreement.

\section{www.reading.ac.uk/centaur}

\section{CentAUR}

Central Archive at the University of Reading

Reading's research outputs online 


\title{
Taking Stock of Neighbourhood Planning in England 2011-2016
}

\author{
Gavin Parker* and Kat Salter \\ School of Real Estate and Planning, \\ University of Reading, UK
}

*Corresponding author: g.parker@ reading.ac.uk

\begin{abstract}
Neighbourhood planning (NP) as enabled by the 2011 Localism Act in England has precipitated a considerable literature discussing its potential, limitations, and likely shortcomings referenced against government rhetoric and the reporting of initial experiences of the process. This paper provides an overview of the current literature on neighbourhood planning and sets out how it has been received and practiced across England drawing on empirical evidence. The extent of take-up and the experience of those involved first five years of neighbourhood planning and to consider how community-led planning may be designed and used following operational principles of inclusivity, capacity-building and adding value.
\end{abstract}

\section{Keywords}

Localism; neighbourhood planning; policy design; capacity; value

\section{Introduction}

In November 2011 the Localism Act reached the statute book. One of the main features of the legislation was the creation of neighbourhood planning (NP) and the associated neighbourhood planning regulations as confirmed in 2012, which allow for communities to produce a Neighbourhood Development Plan (NDP). This new element of the English planning system was intended to enable local residents to formulate their own statutory land use planning policies. The formulation set out in the Act focuses on the neighbourhood as a new locus for deliberation and decision-making in statutory planning in England. Designed as part of an experiment in decentralising planning, NP was badged as part of the then Coalition government's localism agenda. This presented local communities and their partners with a challenge to integrate both national and local priorities and policy with their own 
neighbourhood scale vision. Neighbourhood planning was described by Government as providing:

'...communities direct power to develop a shared vision for their neighbourhood and deliver the sustainable development they need. Parishes and neighbourhood forums can use neighbourhood planning to set policies through neighbourhood plans to determine decisions on planning applications...Neighbourhood planning provides a powerful set of tools for local people to ensure that they get the right types of development for their community' (DCLG, 2012a: para. 183).

Thus exploration here of how neighbourhoods and others have actually responded to the UK government's localism agenda via neighbourhood planning in England in the period 2011-2016 is important as it feeds empirical evidence of practice into debates over the role and impact of neighbourhood planning as well as helping to inform further work.

\section{Localism and Neighbourhood Planning in Overview}

Neighbourhood planning has received considerable attention from the academic and professional practice communities and continues to divide opinion, stimulate discussion and generate critique. While the political and theoretical implications of NP are clearly important to understand and reflect upon, this paper does not explore all of the issues and potentials raised relating to neighbourhood planning. Many have been highlighted in the literature, for example; Brownill and Bradley (2017) in discussing the social purposes of NP; Davoudi and Madanipour (2015) on its ideological credentials; Wills (2016) discussing questions of urban governance; and Bradley and Sparling (2017) and Bailey (2017) on the impact on housebuilding.

Neighbourhood planning was founded on the presumption by government that local people have sufficient interest in planning to invest their time and energy. Moreover, to do so over a sustained period. At the time of its launch governmental rhetoric surrounding NP appeared to downplay asymmetries of knowledge and capacity, or other differences existing one neighbourhood to another. Instead a uniform view of neighbourhood propensities was apparent. Thus, sitting alongside assumptions relating to willingness and capacity, there is a further assumption; that the designated neighbourhood areas will be homogeneous and reflect bounded spatial units containing like-minded people and stable populations (Davoudi and Madanipour, 2013). The conditions and capacities existing across the thousands of very different 'neighbourhoods' in England, provide just some of the cleavages likely to affect engagement with this planning tool (Parker and Murray, 2012; Swyngedouw, 2005; Bailey and Pill, 2015). 
A final assumption is that people are willing to interact to achieve public good outcomes (Bailey and Pill, 2015) and that self-interest will be set aside to develop outcomes that serve a wider interest. This disregards wider structural processes that may disrupt such assumptions, including issues of lack of trust in the system (e.g. Menzel, et al., 2013). Davoudi and Cowie (2013) claim that the self-selective nature of NP groups may result in the favouring of better educated, well-off and more vocal social groups who have the time, capacity and inclination to engage. They have also expressed concern about the legitimacy of unelected bodies acting on behalf of the wider community; especially as they define who they represent by proposing the extent of neighbourhood area. The terms of engagement set out by government act to shape the level of burdens shouldered by participants and concern about motives, ability, range and likely unevenness of take-up have been voiced (see Davoudi and Madanipour, 2013; Gunn et al., 2015; Parker, et al., 2015). This provides a stark contrast to the rhetoric generated by government who aspired to use neighbourhood planning as an important element in making planning more creative, accessible and inclusive (DCLG, 2012a: pi-ii).

Equally the capacity and willingness of Local Authorities (LAs) is another variable and their response to date, given their statutory role as partners in neighbourhood planning, has been mixed with more positive authorities and less supportive ones - which also influences the neighbourhood experience (Healey, 2015; Parker and Salter, 2016). A final issue that has emerged has related to the position and status of NDPs in a planning system that is in almost constant flux; with local plans variously being absent, emerging, requiring updating or being challenged. Parker et al. (2015: p534) identify the need to reflect on the uncertainty that this brings for those involved in producing NDPs.

Within this set of issues the paper focusses on the take-up of neighbourhood planning by communities over the first five years of its operation to inform practice debate. The actual response by communities is reported here based on a compilation of secondary material and some primary data on the take-up and characteristics of neighbourhood plan areas designated by October 2016. Key characteristics of the designated areas were recorded including the type of qualifying body, date of designation, geographic region (including the name of the LPA) and the status of the Local Plan. In order to analyse the socio-economic profile of those engaged in neighbourhood planning the Index of Multiple Deprivation (IMD) 2015 and the Rural Urban Use Classification (RULC) 2011, at the LPA level, was overlaid onto all designated areas. To provide a more detailed analysis IMD and RULC was analysed for the designated neighbourhood areas that had passed referendum by the end of October 2016 (for IMD this was 
based on the average quintile for the LSOA which make up the area boundary). All of the datasets drawn upon are in the public domain. Having provided a detailed overview of take-up we conclude by considering the credentials and outcomes of NP and reflect on the inclusivity, capacity-building potentials and the added value that NDPs can offer.

\section{Neighbourhood planning: the process and the response}

Neighbourhood planning is voluntarily embarked upon, is non-mandatory and as such it is an 'invited space' of participation; one that is designed by government and bounded with a limited scope or freedom for participants (Cockburn, 1977; Gaventa, 2004; Parker, et al., 2015). It relies on the motivation and organising capacities found within a neighbourhood in order to effectively respond. A number of restraints or 'boundary conditions' set the parameters within which groups can operate (Bradley, 2015). A NDP becomes a statutory planning document following a successful referendum and a number of prescribed legislative steps and stages precede this (see Locality, 2016; Smith, 2014; Brownill and Bradley, 2017).

\section{The Take-Up of Neighbourhood Planning}

Governmental assumptions about (inclusive) voluntary take-up have been questioned. This is based partly on the experience of participatory opportunities in the past, and given known variation in capacity and specific issues found across localities. Furthermore, the most organised and articulate i.e. those able to mobilise and draw on networks of social capital, were likely to be most able to manipulate the new environment to serve their own ends. Given the questions outlined above the way in which neighbourhood planning has actually been taken-up five years after its introduction is outlined here. This provides an empirical perspective on the first period of neighbourhood planning on the ground including the socio-economic status of active neighbourhood planning areas.

Clearly neighbourhood planning has been difficult for some communities to grapple with as Gunn et al (2015) highlight, and as discussed in Parker, et al. (2014; 2015). However 1908 neighbourhoods had embarked on neighbourhood planning by the end of October 2016. It was envisaged that unevenness of take-up and possible inequitable outcomes could well result from the design of neighbourhood planning and the untargeted first-come, first served approach to support offered by central government. 
The Department for Communities and Local Government (DCLG) Select Committee Report on the effectiveness of the 2012 National Planning Policy Framework (NPPF), raised a number of points about neighbourhood planning in these regards (House of Commons, 2014). They were strongly supported in principle but it was recognised that they should not become the preserve of the middle classes or of the rural middle class - given that the early wave of neighbourhood planning activity had been dominated by rural (parished) areas (Turley, 2014; Parker. et al., 2014; Parker and Salter, 2016). These dynamics are considered below in reference to time taken to progress NDPs, take-up geographically, characteristics of the groups developing the Plan and through a consideration of Plan content.

\section{Time Taken to Produce a Neighbourhood Plan}

The actual and estimated take-up of neighbourhood planning shown in Figure 1 from Spring 2013 onwards, shows the first periods of take-up to be largely as DCLG had estimated. The take-up year on year shows that while many initiated the neighbourhood planning process, far fewer had progressed to the final stages (i.e. referendum).

\section{Figure 1: Estimated and Actual Take-up of Neighbourhood Planning Areas (2011-2016)}

Ninety-two neighbourhoods had successfully progressed to the referendum stage by Winter 2015 with this rising to 130 by the end of January 2016 and 245 by Autumn 2016. Overall the progress to referendum has been much slower than anticipated, with the time taken to complete (i.e. referendum stage) going well beyond two years in many cases. Indeed, the average (median) time was 29 months. Most of the plans which took less time were led by parishes, and of the 11 plans that took less than 18 months to complete all but one were Frontrunners that had received significant external support. This highlights that NDPs have taken longer than Parish Plans / Community-led Plans (see Parker and Murray, 2012). Ironically the 'light touch' approach that has been advocated by government for neighbourhood planning may have acted to create a degree of confusion rather than enable or expedite progress. The reported difficulties of neighbourhood planning (e.g. Parker, et al. 2014; 2015) has also meant that urban and more deprived communities have been slower to take-up or progress NDPs, or have been deterred by the burdens involved (Gunn et al, 2015). Many groups asked for more support and clarity, which has since prompted a modified approach to the support and advice available via DCLG. This has included increased support for neighbourhood forums and those bringing forward plans in 
areas of deprivation alongside a number of measures to speed up and streamline the process. Participants in the Parker et al. (2014) study also recognised time has to be taken to produce a good quality NDP to ensure a successful examination and a plan robust enough to withstand challenge by the development industry.

\section{The Geography of Neighbourhood Planning Take-up}

By October 20161908 neighbourhood areas had been formally designated and 245 plans had passed the referendum stage (around 300 had passed the examination stage). Figure 2 shows the take-up of neighbourhoods by region. This indicates a larger number of areas were active in the South of England with the South East and South West regions accounting for $41 \%$ of neighbourhood planning take-up overall. Take-up is lowest in the North of England and London (which is entirely un-Parished bar a few new parishes). The number of neighbourhood plans which passed referendum reflects the same North - South disparity. The only marked difference is the higher prevalence of Plans that have passed referendum in the South East (representing $37 \%$ of the overall cohort).

Figure 2: Regional take-up of Neighbourhood Planning: designated areas by region (October 2016)

It is worth noting that no projections or estimates were made about the spread and geographic take-up of NP. The overall cohort shows a marked bias towards parished areas with only 166 areas designated by neighbourhood forums and only 20 Forum-led plans having passed referendum (in both cases representing 9\% of the overall cohort). Analysis of the urban / rural classifications of the plans which had passed referendum by October 2016, based on the Lower Super Output Area (RUC11), also shows a similar bias towards rural areas. Of the 245 plans 83 were produced in areas classified as A1, B1 and C1 (urban), 39 in D1/D2 (rural town), 85 in E1/E2 (rural villages) and the remaining 38 in rural villages / rural towns.

As is clear from the above assessment the progress of Neighbourhood Forums, and to a lesser extent rural areas, has been slow. While little primary research has been conducted it was clear in the Parker et al. (2014) study that groups had found NP burdensome and these statistics tend to correspond to concerns that many urban areas have faced extra hurdles in establishing Forums and agreeing their neighbourhood boundary. While it is recognised that an NDP is not 
necessarily a suitable tool for all areas this may be particularly true for many urban areas and especially where the development market is weaker (Bradley and Haigh, 2015). There are numerous groups who have reportedly stopped work on their NDP and some have opted to use a different approach. North Shields Fish Quay in North Tyneside (a $4^{\text {th }}$ quintile IMD area) was a 2011 NP 'Frontrunner' who, after expending a lot of time working towards a NDP, instead opted to formulate a supplementary planning document. Anecdotally other Forums and parishes have slowed or become moribund for reasons intimated above, and in some cases have been persuaded to wait for their local authority to adopt their local plan - in order to give them more certainty about their policy locus, and perhaps in the hope of a more conducive support environment.

However, in some urban areas there are signs of greater uptake and support - Leeds for example had 35 neighbourhood planning areas active by Autumn 2016 and London as a whole had 73 Qualifying Bodies designated. Further work is needed to understand how some local authorities are enabling and shaping neighbourhood planning in different ways and how some others appear to be downplaying neighbourhood planning.

\section{Diversity of Neighbourhood Planning Take-Up}

As indicated above there have been concerns raised about how more deprived communities may respond to neighbourhood planning given the experience of past engagement efforts. In terms of the socio-economic profile of participating neighbourhood planning groups we have set the cohort of 1908 designated NP areas against the Index of Multiple Deprivation (IMD), at the LPA level, where the fifth quintile (Q5) is the most deprived and the first (Q1) the least deprived areas. The distribution shows that $23 \%$ were ranked in the upper two IMD quintiles, 289 were in the fourth and only 142 in the fifth quintile (7.5\%); leaving $77 \%$ in the lower three quintiles (see Figure 3). This indicates that initial concerns about weaker uptake from disadvantaged areas appears somewhat justified.

Take-up across all regions shows a reasonable spread (as in Figure 2), but the take-up in the South East is markedly skewed towards less-deprived areas (see Figures 3 and 4). It is clear that a more fine-grained examination is needed in order to consider the dynamics and issues faced and way that such issues have been considered in each NP area. 
Figure 3: Index of Multiple Deprivation Breakdown of Neighbourhood Planning Qualifying Bodies at LA level (October 2016)

In terms of the 245 neighbourhoods that had passed the NP referendum by October 2016, these were located in 96 local authority areas spread across the country. Figure 4 provides a more fine-grain indication of their average IMD position based on the LSOA(s) of the designated area. Only six of the neighbourhood areas to have passed referendum were in the $20 \%$ mostdeprived areas in England (Q5) and only 18 (7.3\%) were in the 40\% most-deprived areas (Q4 and Q5). The vast majority of plans (60.8\%) have been produced by those in the $40 \%$ leastdeprived areas (Q1 and Q2).

The level of deprivation can and does vary considerably across a given neighbourhood area. Indeed greater levels of variance across small spatial areas in built-up areas is likely and a more fine-grain analysis of the types of communities taking up neighbourhood planning would yield a clearer picture of the impact that NP is having in and for more deprived sections of the population within all neighbourhoods. A further question remains about which groups or interests in each neighbourhood benefit from the NDP policies and allocations and this will require a case-by-case assessment including the dynamics of intra-community working.

\section{Figure 4: Index of Multiple Deprivation Breakdown of Neighbourhood Planning Areas who had passed the referendum (based on LSOA, October 2016)}

When first introduced a traditional hierarchical approach to plan-making was assumed with neighbourhood plans adding value and distinctiveness to areas with an up-to-date Local Plan in place. However, due to the slow pace of Local Plan making in some areas, of the 245 NDPs which passed referendum by the end of October 2016, 73 were in areas with no up-to-date Local Plan (29\%), a further 21 (9\%) were produced in advance of the Local Plan. This leaves 151 areas $(62 \%)$ having followed the traditional planning hierarchy sequence suggesting that some areas were seeking to fill a policy gap.

Furthermore, based on a sample of 1888 designated neighbourhood planning areas (for which information is available), only 274 neighbourhood areas were designated where the local authority had a post-NPPF (2012) Local Plan in place. Of the sample a group of 476 communities had commenced work on their NDP in areas where the Local Plan pre-dated the 
NPPF (i.e. rendering it much weaker in policy terms) and a further 1138 areas were designated in localities with no up-to-date Local Plan. This gives some indication of mixed take-up but also how a majority were initiating NDPs without an extant Local Plan.

Further work is needed to understand the dynamics and process of neighbourhood plan production in areas without a Local Plan and the implications that this may have on, for example, the working relationship with the LPA, the time-taken to produce the plan, the approach adopted by the group in gathering up-to-date evidence and any potential influence NDPs could have on the emerging Local Plan.

\section{Neighbourhood Plan Policy Content}

We want to reflect on what NDP groups have been seeking to achieve in the policies and allocations made in their Plans. While NDPs are not constrained in theory from including a wide range of policies, government have seen neighbourhood planning as a tool to encourage neighbourhoods to accept further development - particularly housing. In order to offer flexibility and limit associated preparation burdens neighbourhoods are allowed to include as few or as many land use policies as they deem appropriate. As a result the number of policies contained in emerging neighbourhood plans varies considerably (DCLG, 2015; PAS, 2015; Parker and Salter, 2016) and from 2 to 114 policies in our sample of neighbourhood plans that had passed referendum up to October $2016(n=245)$. Some have argued that the policy orientation of those NDPs coming forward have appeared quite balanced with both 'protectionist' and pro-development policy present. However, there are several issues with this interpretation. Most of the 120 Plans considered in the User Experience research (Parker et al, 2014), had policies on housing and over half had allocated sites for housing. When DCLG took a snapshot in December 2015 they calculated that the average number of policies in NDPs stood at 19 (DCLG, 2015) and confirmed that just over half of the NDPs had allocated sites for housing and most (89\%) had policies that addressed local housing - the 'net additionality' question. What remains unclear and somewhat hypothetical is what housing numbers would have been facilitated in any case and therefore whether neighbourhood plans are actually increasing net housing numbers. A small number of NDPs have sought to allocate more housing units in their areas than the local plan identifies (for example Thame, Winsford, Broughton Astley), and when DCLG scrutinised a small number of completed NDPs that had allocated sites for housing they estimated that those neighbourhoods had 'over allocated' compared to the local plan by around 10\% (DCLG, 2015; DCLG, 2016). However, housing need remains a moving target and in some cases, especially where NDPs are being produced in advance of an 
emerging Local Plan, housing policies may not be based on an up-to-date objective assessment of housing need which may limit their longevity.

While a focus on housing numbers is warranted, attention should also be drawn to the type of approach adopted (Bailey, 2017). It is argued that some NDPs have taken the opportunity to advance socially and environmentally sustainable solutions, to prioritise identity, heritage and protection and to ensure local housing needs are met. Thus NDPs are adopting a different way of 'doing' planning with slightly more control over the type, mix and location of new development which is different from the traditional and dominant model of housebuilding in the UK.

Furthermore there are some emerging examples where NDPs have been innovative or otherwise added value to communities (for example see; Bradley, Burnett and Sparling, 2017; PAS, 2015) and a better understanding of how and why such innovation has been possible is needed. This is made more pertinent given concerns about the susceptibility of NDPs to policy change and how in turn this affects their value or resilience in planning decision-making.

\section{Discussion and Conclusion: Navigating Neighbourhood Planning}

Our review suggests that while there is interest and growing neighbourhood planning activity it is still being met with caution. In terms of principles of inclusivity, capacity-building and value-adding after five years; around $10 \%$ of the neighbourhoods who could have initiated a neighbourhood plan had done so and across this group a mixed picture has formed. The majority of those active are in parished areas, and while the spread across regions has become a little more even over time, the number of Forums (urban areas) remains low and reported issues relating to urban take-up are in line with the data presented here.

While the socio-economic profile of participating areas is predominately taken at local authority scale, this does provide an indication of the affluence or deprivation of active areas and in turn highlights how much is still to be done to address inclusivity and maximise on the capacity building possibilities that neighbourhood planning may afford. The profile of the group of 245 post-referendum NDPs 245 shows a large majority of less-deprived areas who have managed to complete the process and highlights a marked bias towards Plans produced in rural areas. This is hardly surprising given the way that support money was organised until 2015 and reflects concerns about the asymmetries of knowledge and capacity existing between neighbourhoods. 
DCLG are now shifting towards encouraging greater peer-learning and support for neighbourhood planning activity in response to the skewed take-up of neighbourhood planning. Recent resource and support tweaks recognise a need to prioritise support, with some targeting on 'priority' areas; including more deprived areas, neighbourhood forums and areas of growth. Given the scale of modifications at examination (Parker et al., 2016) and other difficulties faced by the first waves of neighbourhood planners there are questions still about the ability of (some) neighbourhoods to produce successful Plans despite support. One response is emerging guidance on examinations that may stiffen the process further (Parker, Salter and Hickman, 2016).

Thus scrutiny and assessment criteria for neighbourhood planning needs further attention. The measures for assessing this planning experiment cannot only rest on the number of Plans produced despite this has being the prime concern of Ministers. Beyond this quantitative measure the aim of government has been to enable growth: do NDPs aid growth and identify new sites i.e. meet a 'net additionality' criterion? Furthermore, do they engender localist ownership, promote understanding of planning, feed into and improve local plan production? This brings us closer to the question of whether this planning tool is likely to help address the housing crisis? The answer based on evidence thus far suggests not; with even the most prodevelopment examples of NDPs providing small net gains in housing allocation. This begs a question about whether there is a need to rethink the NP approach more radically; perhaps to link neighbourhood planning with other more strategic processes and incorporate this with local plan making more overtly. These shifts have been discussed by Government in the Housing White Paper (DCLG, 2017) which considered: measures to strengthen the role of neighbourhood planning and includes proposals to enable groups to obtain a housing requirement figure from their LPA; changes to national policy to highlight opportunities for NDPs to identify and allocate suitable housing sites; and reducing the scope for NDPs to be undermined by changing the way land supply for housing is assessed. There may also be merit in NP support being more targeted to ensure that it is both beneficial and good quality (i.e. robust in terms of process and product) and encouraged more in areas with specific needs.

Thus our review highlights that there are still clearly many questions still to be pursued about the value of neighbourhood planning in its current manifestation, including the following:

- Who benefits from the neighbourhood plan and whose interests are represented in it?

- What value-added / net additionality are NDPs providing? i.e. beyond the local plan.

- What attitudes and support arrangements are local authorities exhibiting towards NP and why? 
- What oversight and quality of process and organisation of the examination and examiners are in place - given the way that NP examinations have operated thus far?

- What alternative tools are being used to engage communities and to plan locally where NPs are not being taken up? And to what effect?

- How may neighbourhood planning be integrated into the wider planning system better - in terms of the relationship with local plans and local plan processes.

Even if a broader cross-section of neighbourhoods do take up NP, it is still questionable whether it is truly the best use of the energies of neighbourhoods, or whether they could be equally well served as part of a project to instil planning as an important part of civics including, for example, a wider emphasis on engagement processes and more direct input to local plan-making. The outcomes to be derived from neighbourhood planning are also questionable given the unstable nature of planning implementation, the shifting requirements for evidence and the relationship with (changing) local plans. All of these issues may undermine the robustness of NDPs and while further research will help establish a more refined picture of this experiment, our view is that a major rethink about how to actively mobilise wider inputs to plan-making is needed.

\section{References}

Bailey, N. and Pill, M. (2015) 'Can the State empower communities through Localism? An evaluation of recent approaches to neighbourhood governance in England'. Environment and Planning C: Government and Policy, 33(2): 289-304.

Bailey, N. (2017). Housing at the neighbourhood level: a review of the initial approaches to neighbourhood development plans under the Localism Act 2011 in England. Journal of Urbanism: International Research on Placemaking and Urban Sustainability, 10(1), 1-14.

Bradley, Q. (2015) 'The political identities of neighbourhood planning in England', Space and Polity, 19(2): 97-109.

Bradley, Q. and Haigh, D. (2016) 'Sustainable communities and the new patchwork politics of place' in Dastbaz, M., Strange, I. and Selkowitz, S. (eds) Building Sustainable Futures. Springer, Dordrecht.

Bradley, Q., Burnett, A. and Sparling, W. (2017) 'Neighbourhood planning and the spatial practices of localism', pp57-74 in Brownill, S. and Bradley, Q. (eds.) Localism and Neighbourhood Planning. Power to the People? Policy Press, Bristol.

Bradley, Q. and Sparling, W. (2017) The impact of neighbourhood planning and localism on house-building in England. Housing, Theory and Society, 34(1): 106-118.

Brownill, S. and Bradley, Q. (eds) (2017) Localism and Neighbourhood Planning. Power to the People? Policy Press, Bristol.

Cockburn, C. (1977) 'The local state: management of cities and people' Race and Class, 18(4): 363-376.

Davoudi, S. and Cowie, P. (2013) 'Are English Neighbourhood Forums Democratically Legitimate?', Planning Theory and Practice, 14(4): 562-566. 
Davoudi, S. and Madanipour, A. (2013) 'Localism and Neo-liberal Governmentality', Town Planning Review, Vol. 84(5): 551-562.

Davoudi, S. and Madanipour, A. (eds.) (2015) Reconsidering Localism. Routledge, London.

DCLG [Department of Communities and Local Government] (2012a) National Planning Policy Framework. April 2012. HMSO, London.

DCLG [Department of Communities and Local Government] (2012b) Neighbourhood Planning Impact Assessment. TSO, London.

DCLG [Department of Communities and Local Government] (2015) Notes on Neighbourhood Planning No.17, December 2015. At: https://www.gov.uk/government/publications/notes-onneighbourhood-planning-edition-17 [last accessed 17/11/16]

DCLG [Department of Communities and Local Government] (2016) Neighbourhood Planning: progress on housing delivery. October 2016 edition. At: https://mycommunity.org.uk/wpcontent/uploads/2016/08/161013-made-neighbourhood-plan-housing-delivery_Oct2016.pdf

[last accessed 28/07/17]

DCLG [Department of Communities and Local Government] (2017) Fixing our broken housing market. February 2017. DCLG, London.

Gaventa, J. (2004) 'Towards participatory governance: assessing the transformative possibilities' pp25-41, in Hickey, S. and Mohan, G. (eds.) Participation: from tyranny to transformation? Zed books, London.

Gunn, S., Brooks, E., and Vigar, G. (2015) 'The Community's Capacity to Plan: the disproportionate requirements of the new English Neighbourhood Planning initiative' pp147167 in Davoudi, S. and Madanipour, A. (eds.) Reconsidering Localism. Routledge.

Healey, P. (2015) 'Civic capacity, place governance and progressive localism', pp105-125 in Davoudi, S. and Madanipour, A. (eds.) (2015) Reconsidering Localism. Routledge, London.

House of Commons (2014) Select Committee Report on the National Planning Policy Framework. (HC190) DCLG / House of Commons, December 2014. TSO, London.

Locality (2016) Neighbourhood Planning Roadmap Guide. At http://mycommunity.org.uk/wpcontent/uploads/2016/08/NP-Roadmap-Pages-web.pdf [last accessed 22/11/2016]

Menzel, S., Buchecker, M. and Schulz, T. (2013) 'Forming social capital. Does participatory planning foster trust in institutions? Journal of Environmental Management, 131: 351-362.

Parker, G. and Murray, C. (2012) 'Beyond tokenism? Community-led planning and rational choices: findings from participants in local agenda-setting at the neighbourhood scale in England' Town Planning Review, 83(1): 1-28.

Parker, G., Lynn, T., Wargent, M. and Locality (2014) User Experience of Neighbourhood Planning in England. October 2014. Locality, London.

Parker, G., Lynn, T. and Wargent, M. (2015) 'Sticking to the script? The co-production of Neighbourhood Plans', Town Planning Review, 86(5): 519-536.

Parker, G. and Salter, K. (2016) 'Five years of neighbourhood planning. A review of take-up and distribution'. Town and Country Planning, 85(5): 175 - 184

Parker, G., Salter, K. and Hickman, H. (2016) 'Caution: Examinations in progress': the operation of Neighbourhood Plan Examinations in England.' Town and Country Planning, 85(12): 516-522. 
PAS [Planning Advisory Service] (2015) Note on issues from emerging neighbourhood plans - some case studies. March 2015. At: http://www.pas.gov.uk/web/pas1/neighbourhoodplanning/- /journal_content/56/332612/7122302/ARTICLE [last accessed 14/09/16]

Smith, L. (2014) Neighbourhood Planning. House of Commons Library Standard note: SN/SC/5838, July 2014. House of Commons, London.

Swyngedouw, E. (2005) 'Governance, Innovation and the Citizen: the Janus Face of Governance-beyond-the-State'. Urban Studies, 42(11): 1991-2006.

Turley (2014) Neighbourhood Planning: Plan and Deliver? March 2014. Turley Planning Consultancy, Bristol.

Wills, J. (2016). Locating localism: Statecraft, citizenship and democracy. Policy Press 


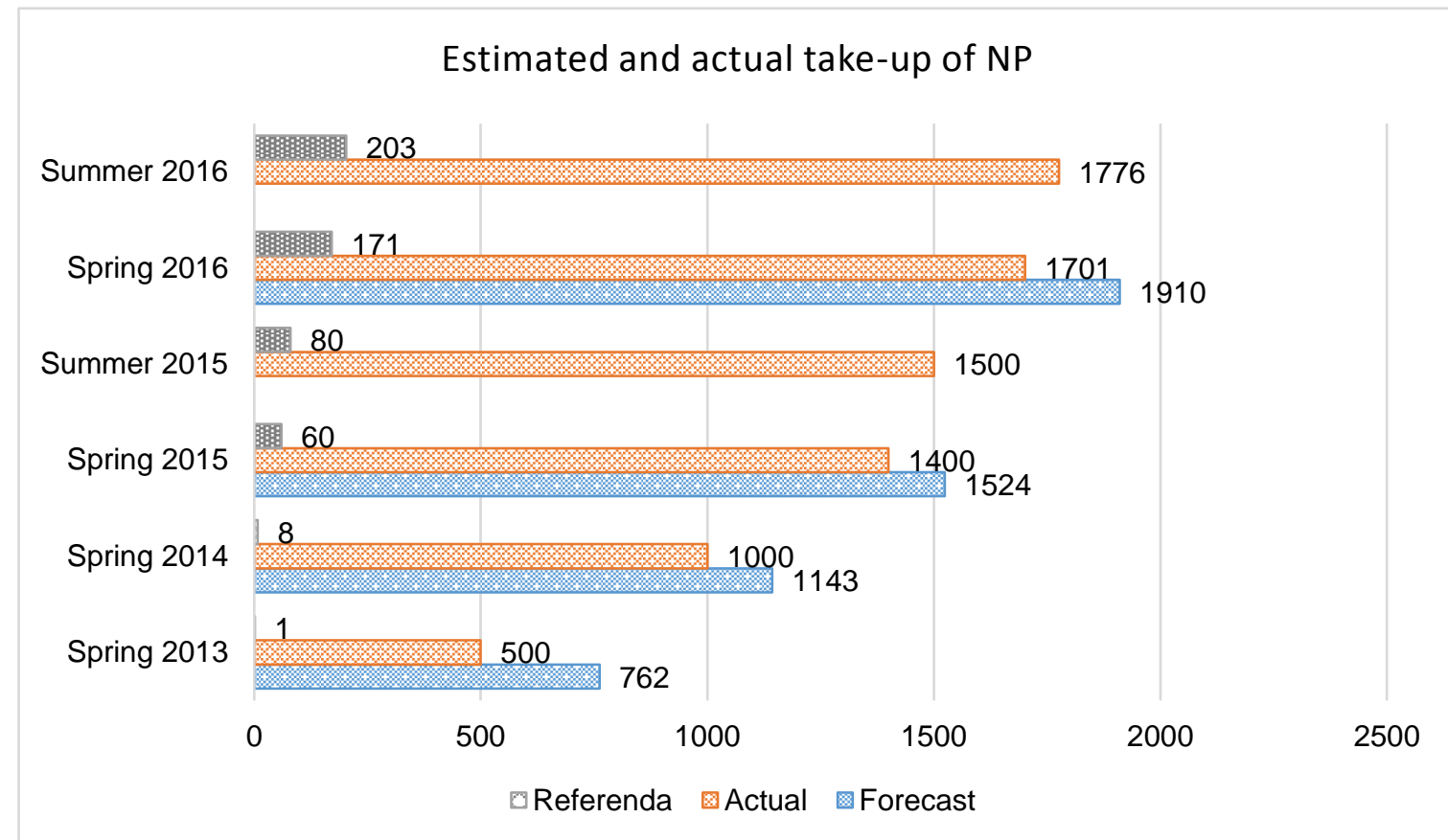

Note: based on DCLG, 2012a, successive 'Neighbourhood Planning notes' produced by DCLG) and data collected by the authors.

Figure 2: Regional take-up of Neighbourhood Planning: designated areas by region (as at October 2016)

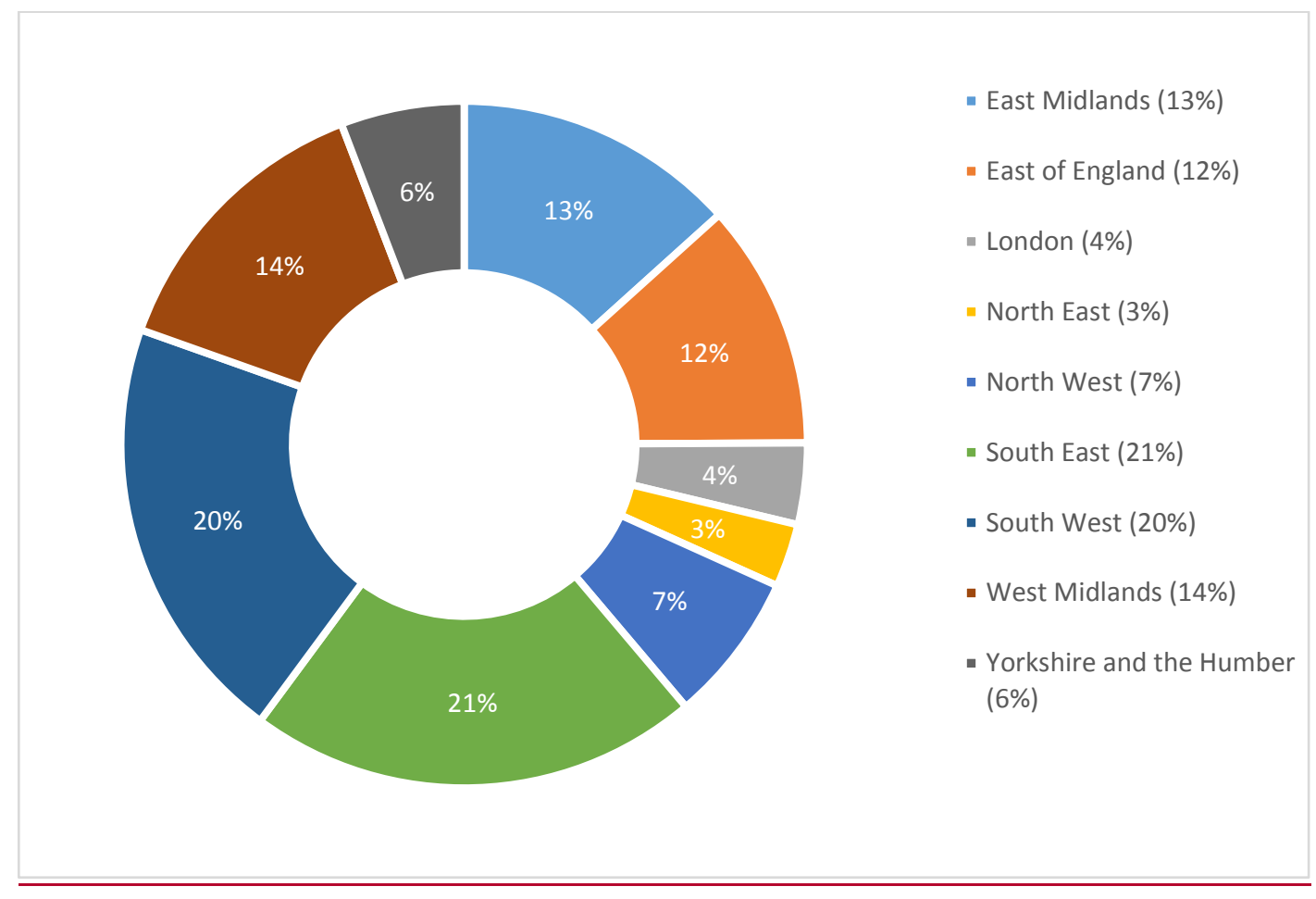

$(n=1908)$ 
Figure 3: Index of Multiple Deprivation Breakdown of Neighbourhood Planning Qualifying Bodies at LA level (October 2016)

\begin{tabular}{|c|c|c|c|c|c|c|}
\hline $\begin{array}{l}\text { Region } \\
\text { (Population) }\end{array}$ & $\begin{array}{l}\text { IMD } \\
\text { Q1 }\end{array}$ & $\begin{array}{l}\text { IMD } \\
\text { Q2 }\end{array}$ & $\begin{array}{l}\text { IMD } \\
\text { Q3 }\end{array}$ & $\begin{array}{l}\text { IMD } \\
\text { Q4 }\end{array}$ & $\begin{array}{l}\text { IMD } \\
\text { Q5 }\end{array}$ & Totals \\
\hline $\begin{array}{l}\text { London } \\
(8.174 \mathrm{~m})\end{array}$ & 1 & 2 & 2 & 20 & 48 & 73 \\
\hline $\begin{array}{l}\text { South East } \\
(8.635 \mathrm{~m})\end{array}$ & 255 & 61 & 62 & 23 & 5 & 406 \\
\hline $\begin{array}{l}\text { South West } \\
(5.289 \mathrm{~m})\end{array}$ & 52 & 152 & 89 & 86 & 9 & 388 \\
\hline $\begin{array}{l}\text { West Midlands } \\
(5.602 \mathrm{~m})\end{array}$ & 46 & 27 & 163 & 20 & 7 & 263 \\
\hline $\begin{array}{l}\text { East Midlands } \\
(4.533 \mathrm{~m})\end{array}$ & 63 & 106 & 47 & 26 & 12 & 254 \\
\hline $\begin{array}{l}\text { East of England } \\
(5.847 \mathrm{~m})\end{array}$ & 70 & 77 & 45 & 22 & 7 & 221 \\
\hline $\begin{array}{l}\text { Yorks \& Humber } \\
(5.284 \mathrm{~m})\end{array}$ & 3 & 18 & 10 & 50 & 30 & 111 \\
\hline $\begin{array}{l}\text { North West } \\
(7.052 \mathrm{~m})\end{array}$ & 3 & 67 & 33 & 15 & 17 & 135 \\
\hline $\begin{array}{l}\text { North East } \\
(2.597)\end{array}$ & 0 & 0 & 23 & 27 & 7 & 57 \\
\hline $\begin{array}{l}\text { England } \\
(\mathbf{5 3 . 8 6 5 m})\end{array}$ & $\begin{array}{l}493 \\
(25.8 \%) \\
\end{array}$ & $\begin{array}{l}510 \\
(26.7 \%) \\
\end{array}$ & $\begin{array}{l}474 \\
(24.9 \%) \\
\end{array}$ & $\begin{array}{l}289 \\
(15.1 \%)\end{array}$ & $\begin{array}{l}142 \\
(7.5 \%)\end{array}$ & $\begin{array}{l}\begin{array}{l}1908 \\
(100 \%)\end{array} \\
\end{array}$ \\
\hline
\end{tabular}

(Note: based on 2015 IMD classifications and ONS 2013 population projections. Q1 = least deprived / Q5 = most deprived)

Figure 4: Index of Multiple Deprivation Breakdown of Neighbourhood Planning Areas who had passed the referendum (based on LSOA, October 2016)

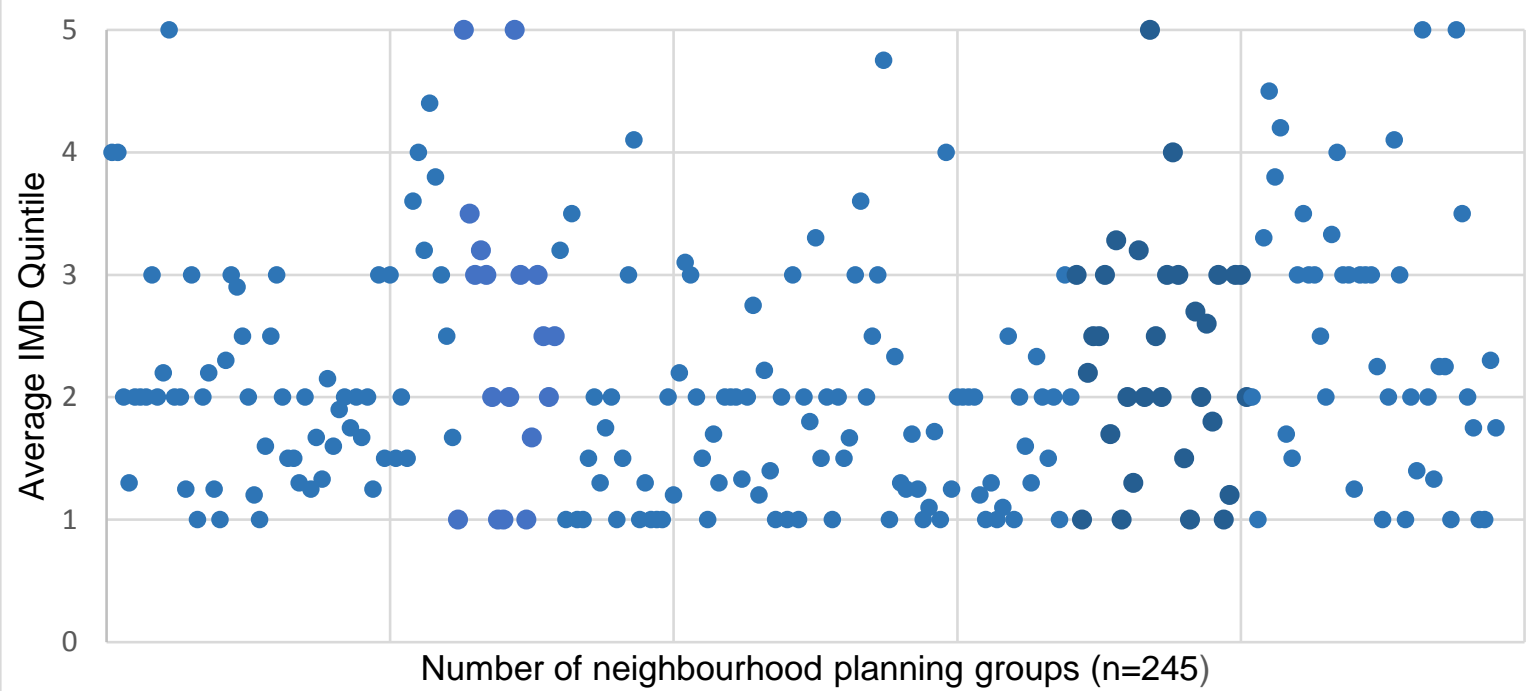


Index of Multiple Deprivation Breakdown of Neighbourhood Planning

Areas who had passed the referendum (based on LSOA, October 2016)

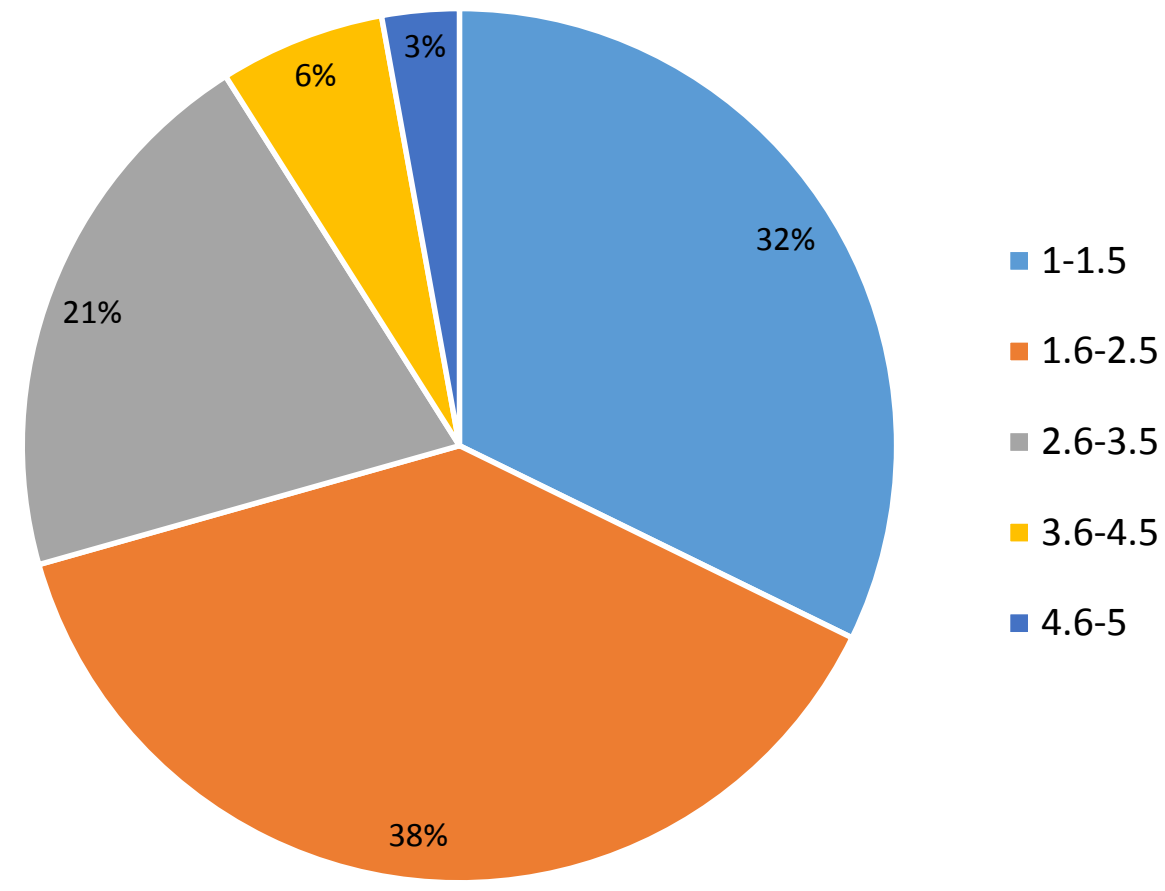

